\title{
EL SATURNISMO Y LA CAÍDA DEL IMPERIO ROMANO
}

Antonio Aguilera Martín ${ }^{1}$

\section{Resumen}

Durante muchos años, y de forma recurrente, algunos estudiosos de la historia de Roma han considerado que el saturnismo (envenenamiento por plomo) provocado por la ingesta de vino conteniendo arrope, fue una de las causas principales de la locura de algunos emperadores romanos, de la falta de natalidad de su aristocracia o incluso de la caída del imperio romano. En este trabajo se demuestra lo contrario, pues el arrope fue utilizado por los romanos sólo en la fabricación de vinos de mala calidad. Por tanto, precisamente el saturnismo actuó sobre todo entre las capas más desfavorecidas de la población, nunca sobre las clases altas.

\section{Palabras clave}

Saturnismo, arrope, aristocracia romana

\section{Resumo}

Durante muitos anos, e de forma recorrente, alguns estudiosos da história de Roma consideraram que o saturnismo (envenenamento por chumbo) provocado pela ingestão de vinho contendo mosto, foi uma das causas principais da loucura de alguns imperadores romanos, da falta de natalidade de sua aristocracia ou, inclusive, da queda do império romano. Neste trabalho se demonstra o contrário, pois o mosto foi utilizado pelos romanos só na fabricação de vinhos de má qualidade. Portanto, precisamente o saturnismo atuou, sobretudo, dentre as camadas mais desfavorecidas da população, nunca sobre as classes altas.

\section{Palavras-chave}

Saturnismo; mosto; aristocracia romana. 1 Profesor Doctor, Universitat de Barcelona, Barcelona, España. E-mail:
$\underline{\text { antonioaguilera@ub.edu }}$ 
Conocí a P.P.A. Funari en el curso 1989-90, siendo yo estudiante de último año en Barcelona. Se anunciaba una conferencia sobre grafitos pompeyanos que impartía un profesor de Brasil y fui con curiosidad a verlo, pues nunca pensé que allí nadie se dedicase a esta área de conocimiento. Pero la conferencia de Pedro Pablo me convenció de que en Brasil vivía al menos una rara avis que estaba a la altura de los investigadores europeos dedicados a la Historia Antigua. Aquella rara avis me obligó a conocer cómo funciona la onomástica en portugués, pues a partir de entonces se convirtió en uno de los autores que he tenido que citar a lo largo de mi carrera investigadora.

Pero, como no podía ser de otro modo, Funari no era una rara avis. Pronto, tras él, comenzaron a llegar a Barcelona algunos de sus incontables alumnos, a muchos de los cuales considero entre mis amigos (entre ellos y especialmente a Renata Garrafoni y Claudio Carlan, a Marina Cavicchioli, Lourdes Feitosa, etc.). Y este, quizá, es el mayor logro de Funari: el haber creado una escuela de historiadores de la antigüedad en Brasil. Se trata de una escuela que Funari ha ido criando con inteligencia $\mathrm{y}$, sobre todo, con mucho esfuerzo. Una escuela cuyos miembros han viajado a numerosos centros de investigación europeos y que ha contribuido a que los estudios de historia antigua sean hoy algo corriente en Brasil.

Después de su primera conferencia, Funari vino a Barcelona muchas veces y con él he coincidido también en otros lugares. Conocí entonces a la persona. Uno de nuestros contactos más entrañables fue un viaje que realizamos juntos desde Barcelona hasta Klagenfurt, en Austria, con la intención de participar en un congreso sobre epigrafía. Fuimos junto con José Remesal y Piero Berni, en avión desde Barcelona hasta Venecia y desde allí con un coche alquilado atravesando los Alpes, puesto que el viaje era así más barato. En el camino de vuelta a Venecia dormimos en Bruneck, en casa de un auténtico tirolés, el profesor H.J. Ulb, de la universidad de Viena, viejo amigo de Remesal. 


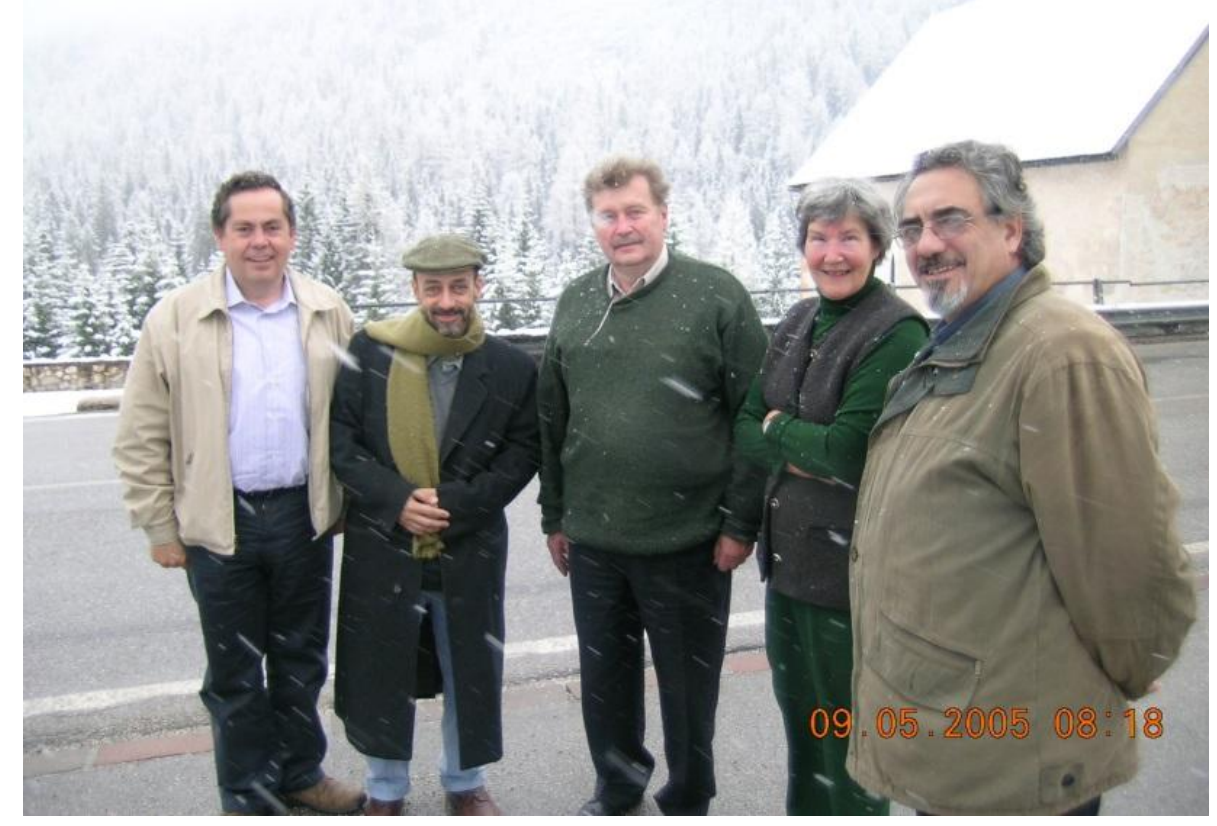

Allí Pedro Pablo me pidió que le hiciera una foto "porque en Brasil no iban a creen que él había conducido en una carretera nevada".

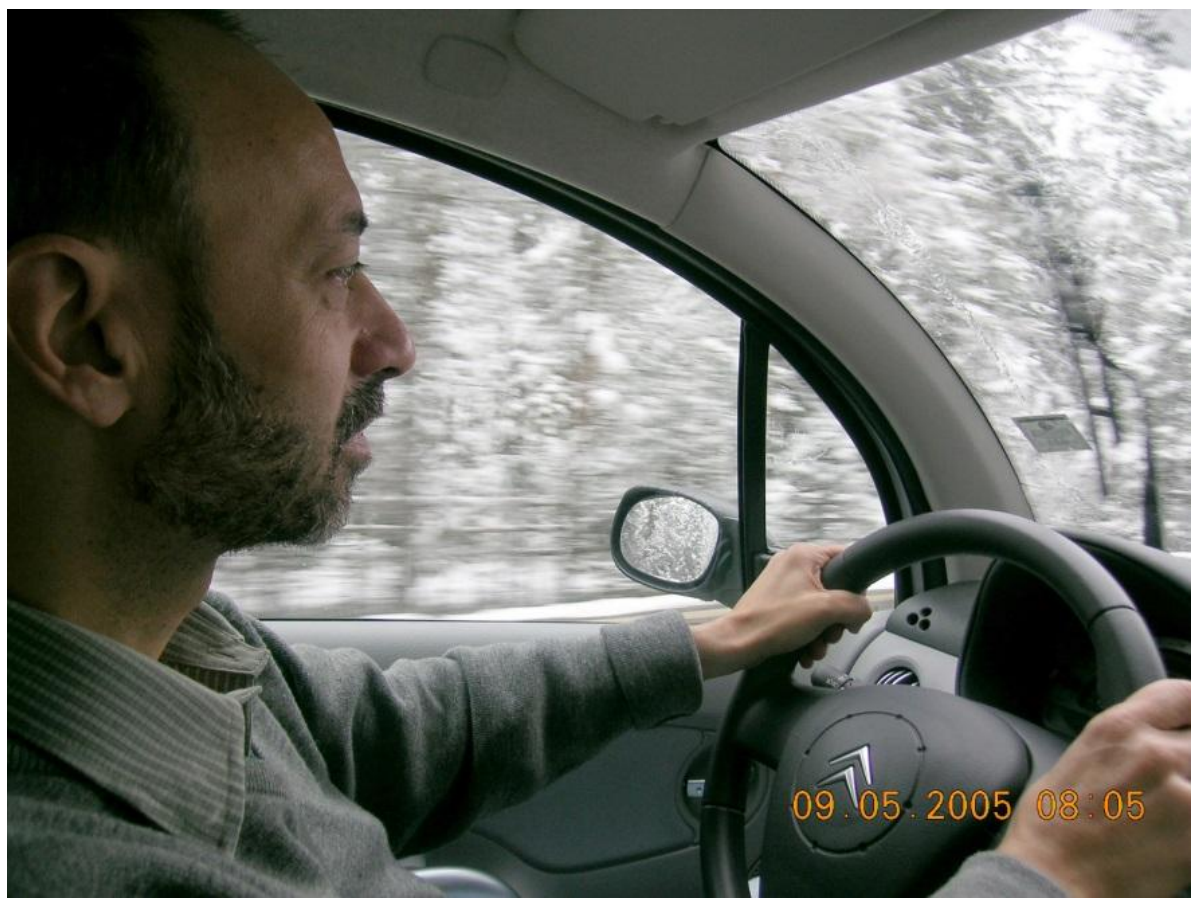

Otro hito importante en nuestra relación fue durante mi viaje a Brasil en 2012. Llegué invitado por la colega y amiga Margarida María de Carvalho con la intención de impartir allí una asignatura sobre "Raíces y evolución de la alimentación europea" dentro del curso de postgrado en Historia de 
la Universidad de Franca. Aprovechamos para dar algunas conferencias por el país y la primera fue en Campinas, el 12 de marzo, recién llegado de un viaje de 26 horas procedente de Barcelona. Mi primera conferencia en Campinas tuvo como tema la calidad del vino que bebían los antiguos romanos. Por ello me gustaría tratar un tema que recurrentemente ha ido apareciendo a lo largo del tiempo, especialmente entre aquellos investigadores que desconocen las fuentes literarias romanas $\mathrm{y}$, sobre todo, el proceso por el que se obtiene el vino. La idea a discutir es la de que el envenenamiento por plumbosis fue el causante de la locura de algunos emperadores romanos y de, incluso, la caída del imperio romano ${ }^{2}$.

A pesar de que las primeras descripciones médicas sobre el envenenamiento por plomo aparecen en la literatura médica clásica y de que tanto griegos como romanos conocían el peligro que representaba el plomo33, la etiología correcta de la dolencia no se reveló hasta 1656, cuando el alemán Samuel Stockhausen estudió la enfermedad profesional que sufrían los trabajadores de las minas de Rammelsberg, en la Baja Sajonia 4 . No era la primera vez que la enfermedad aparecía en época moderna. Ya en 1616 Citoys, médico personal del cardenal Richelieu, la había descrito, denominándola Colicum Pictonum por azotar desde 1572 la antigua región de Poitou ${ }^{5}$. De hecho, la enfermedad aparecía y desaparecía en muchos lugares de Europa y de América, de forma que se la llegó a denominar de muy diversas formas: Colicum pictonum, de Poitou, de Devonshire, de Madrid, de Normandía, de Cayenne, cólico

2 El saturnismo o plumbosis es un envenenamiento causado por la ingesta de plomo, que provoca trastornos mentales, físicos y hasta la muerte. Causa anemia, alucinaciones, ataques de locura, y daños neurológicos irreversibles cuando llega al cerebro.

${ }^{3}$ Nicando de Colofón (s. II a.C.), en su obra Alexipharmaca 2.74ss. hablaba del plomo como elemento "brillante, blanco, mortal, como la leche". Producía espuma en la boca, aspereza en la lengua y sequedad en la garganta, arcadas, escalofríos, delirios, etc.; Celso (s. I a.C.) De medicina, 5.27.12b considera la cerusa o "blanco de plomo" entre los venenos; PauloAegineta (s. VII d.C.), De Re Medica Libri Septem, 3.43 (Sobre el cólico): "Soy de la opinión de que este cólico (...) ha surgido en Italia, pero también en muchas otras regiones del imperio romano, como un contagio pestilente, que en muchos casos termina en epilepsia, pero en otros en parálisis de las extremidades".

${ }^{4} \mathrm{~S}$. Stockhausen, Libellus de lithargyrii fumo noxio morbifico ejusque metallico frequentiori morbo vulgo dicto die Hüttenkatze, Goslar, 1656.

${ }^{5} \mathrm{Al}$ oeste de Francia, entre Poitiers y el Atlántico. La enfermedad se extendió por la región durante más de 60 años y luego se atenuó, para extenderse más tarde por otros lugares de Francia. F. Citoys, De novo et populari apud Pictones dolore colico bilioso diatriba, Paris 1616. Citoys notó que su aparición en Poitou coincidió con la visión de una nueva estrella en la constelación de Casiopea, instrumentalizando esta casualidad para considerar esta aparición como un castigo divino a un mundo pecaminoso. 
saturnino, metálico, de los pintores, de los plomeros, vegetal de las Indias, etc.

El conocimiento de que todas estas enfermedades estaban provocadas por la misma causa se tuvo cuando en 1696 Gockel comprobó que determinados métodos utilizados para "corregir" vinos deficientes estaban en el origen de la misma. Gockel lo descubrió al comprobar que en un monasterio donde los monjes tenían la misma dieta, aquellos que no bebían vino tenían buena salud, mientras que los que lo bebían caían víctimas de los dolorosos cólicos ya conocidos desde antiguo (Colica Pictonum $)^{6}$. En efecto, ese año se produjeron en el sur de Alemania una serie de brotes de plumbosis relacionados con condiciones climáticas (que potenciaron) y políticas (que permitieron) que los vinos fuesen adulterados con la adición de "azúcar de plomo". Este acetato de plomo o litergirio se añadía a los vinos defectuosos o directamente al vinagre para venderlo como vino. Como más tarde dice el diccionario Fabre, citando a Tanquerel: Mais aucune substance n'a plus fréquemment donné lieu à la colique saturnine que les vins frelatés avec le litharge ou la céruse. Toutefois, dit M. Tanquerel, depuis que des mesures de police furent prises pour découvrir la falsification, on ne vit plus de coliques épidémiques causées par les vins durs et acerbes7.

El primero en hablar del envenenamiento por plomo en el mundo romano fue el inglés Henderson, quien hablando de la adulteración que se hacía en su época de los vinos que consumían las clases más pobres se remonta a la época romana para demostrar que ya en esa época también se adulteraban 8 . Otros también trataron el mismo problema, como el austriaco Hofmann o su discípulo alemán Kobert, quien ya avanzó algo de la extravagante idea que tomó fuerza sólo en el siglo siguiente9. Así, hasta 1965 no creció con fuerza la creencia de que la caída del Imperio Romano, la "locura" de algunos de sus emperadores y la baja natalidad

6 E. Gockel, "De vini acidi per acetum lithargyri cum maximo bibentium damno dulcificatione", Ephemerides (Misc Curiosa). Dec. III, Ann. 4, Obs 30, 1697, pp.77-85; Idem, Eine curiose Beschreibung dess an 1694, 95, und 96, durch das Silberglett versüssten sauren Weins und der davon entstandenen neuen und vormals unerhörten Wein-Krankheit, Ulm, 1697.

7 A. Fabre (ed.), Dictionnaire des dictionnaires de médecine français et étrangers ou traité complet de médecine et de chirurgie pratiques, par une société de médecins, Paris 1850, p. 74.

8 A. Henderson (1824), History of Ancient and Modern Wines, London 1824, p. 338-339.

9 K. B. Hofmann (1883), "Die Getränke der Griechen und Römer vom hygienischen Standpunkte", Deutsches Archiv für Geschichte der Medizin und medicin, 6, 269ss.; K. B. Hofmann (1885), Das Blei bei den Völkern des Altertums; R. Kobert (1886), Ueber den Zustand der Arzneikunde vor 18 Jahrhunderten; R. Kobert (1909), "Chronische Bleivergiftung im klassischen Atertum", en P. Diegart (ed.), Beiträge aus der Geschichte der Chemie, 103-119. 
de la aristocracia romana se debían todas a la misma causa: el envenenamiento por plomo. Así, Gilfillan en 1965 y más tarde Nriagu en 1983 y tras ellos algunos otros ${ }^{10}$, consideraron que los romanos, en especial sus clases dirigentes, desconocían los peligros del plomo y cayeron víctimas de este desconocimiento, lo que no es en absoluto lógico ${ }^{11}$.

En particular los autores a favor de esta teoría consideraron dos fuentes principales de envenenamiento: la utilización de cañerías de plomo en la distribución del agua en las ciudades romanas y la utilización de calderas de plomo para la fabricación del azúcar de los pobres romanos, el defrutum.

La primera de las causas, el uso de tuberías de plomo en la conducción del agua de las ciudades romanas, expondría al envenenamiento no sólo a las clases dirigentes sino también a toda la población. Es más, los romanos conocían el problema por lo que siempre estuvieron alerta sobre él, como claramente refiere el ingeniero y arquitecto Vitrubio (s. I a.C.) ${ }^{12}$ :

(...) el agua conducida por tuberías de barro es mucho más saludable que la que llega por tubos de plomo, pues el plomo es más perjudicial al facilitar la presencia de la cerusa que, según dicen, es nociva para el cuerpo humano. Por tanto, si lo que genera el plomo es perjudicial, no cabe la menor duda de que también el plomo será nocivo. Podemos aportar el ejemplo de los que trabajan con plomo, observando que tienen la piel completamente pálida. Cuando funden el plomo, el vapor que despide penetra por todos los miembros del cuerpo y va minando la energía de la sangre. En consecuencia, no parece conveniente usar tuberías de plomo para conducir el agua si queremos que ésta

10 S.C. Gilfillan, (1965) "Lead Poisoning and the Fall of Rome", Journal of Occupational Medicine, 7, 53-60; S.C. Gilfillan, (1990) Rome's Ruin by Lead Poison; J.O. Nriagu (1983), "Saturnine Gout Among Roman Aristocrats: Did Lead Poisoning Contribute to the Fall of the Empire?", New England Journal of Medicine, 308, 660-663; J.O. Nriagu (1983), "Occupational Exposure to Lead in Ancient Times", The Science of the Total Environment, 31(2), 105-116; J.O. Nriagu (1983), Lead and Lead Poisoning in Antiquity; J.O. Nriagu (1998), "Clair Patterson and Robert Kehoe's paradigm of 'Show me the data' on environmental lead poisoning". Environ. Res., 78, 71-78.

${ }^{11}$ En contra puede verse la obra de Scarborough, quien llegó a decir de Nriagu que su trabajo estaba "tan lleno de pruebas falsas, mistificaciones, errores tipográficos y una flagrante ligereza con respecto a las fuentes primarias que el lector no puede confiar en los argumentos básicos", llegando a la conclusión que el saturnismo no fue algo endémico en el impero romano y menos la causa de su caída. De la misma idea son Waldron o Needleman: J. Scarborough, (1984) "The Myth of Lead Poisoning Among the Romans: An Essay Review", Journal of the History of Medicine, 39, 469-475; H.A. Waldron (1973), "Lead Poisoning in the Ancient World", Medical History, 17, 391-399; D. Needleman, L. Needleman (1985), "Lead Poisoning and the Decline of the Roman Aristocracy", Classical Views, 4(1), 63-94.

12 VITRUBIO 8.6.10-11. 
sea salubre. La comida que consumimos cada día permite constatar que el agua tiene mejor gusto si se conduce por medio de tubos de barro, pues todo el mundo, aunque dispongan de mesas preparadas con vasos de plata, sin embargo utilizan recipientes de barro para conservar mejor el sabor y la pureza del agua.

Además, los romanos no utilizaban los grifos, que cortan y estancan el agua corriente, de forma que apenas sufrieron los efectos de un contacto prolongado con el plomo. La confirmación de esto la dan los recientes análisis de isótopos de plomo hechos a los sedimentos de esa época encontrados en el fondo del río Tíber y del vecino puerto de Trajano: A pesar de constatar que el agua que transportaban las tuberías de plomo contenía al menos 100 veces más plomo que el agua de lluvia, los investigadores concluyen que: "Lead pollution of 'tap water' in Roman times is clearly measurable, but unlikely to have been truly harmful"13.

La segunda supuesta fuente de envenenamiento de emperadores y aristocracia romana sería el consumo de defrutum. Pero precisamente el desconocimiento de lo que es el defrutum y, sobre todo, de sus usos, han hecho pensar a muchos autores modernos que los ricos romanos bebían vino que contenía ese producto ${ }^{14}$. Nada más lejos de la realidad. Pero, para conocer qué es en realidad el defrutum y para qué sirve, tenemos que saber primero que el factor más importante en la calidad de un vino es la luz solar que recibió la uva. Si no hay suficiente sol, la uva no produce suficientes azúcares y sin éstos la fermentación alcohólica creará un vino con poca estabilidad y con muchas posibilidades de sufrir enfermedades.

En principio, cuanto más alta sea la riqueza en azúcares del mosto o zumo de la uva, más riqueza alcohólica tendrá el vino. Del mismo modo, cuanto más alta sea esta riqueza, más difícil será el picado o avinagrado del vino, aunque sólo en los vinos de más de $16^{\circ}$ no existe ese peligro ${ }^{15}$. Por ello, con la finalidad de compensar los casos de insuficiente maduración de las uvas, los enólogos han buscado siempre completar el fenómeno natural de la maduración exaltando los fenómenos bioquímicos normales de la maduración mediante sobremaduración de la

${ }^{13}$ H Delile, J. Blichert-Toft, J.Ph. Goiran, S. Keay, F. Albarède (2014),: "Lead in ancient Rome's city waters", Proceedings of the National Academy of Sciences, 111, 6.594-6.599.

14 Por ejemplo S. Bhattacharjee (2009), "A brief history of gout", International Journal of Rheumatic Diseases, 12, 61-63. O incluso C. M. Cipolla, Allegro ma non troppo, 1996, p. 67.

${ }^{15}$ L. Ibar (2002), Cómo se hace un buen vino, Barcelona, 159ss. 
uva ${ }^{16}$ o efectuando una corrección del mosto para que éste adquiera una composición química vecina a la obtenida con una buena maduración ${ }^{17}$.

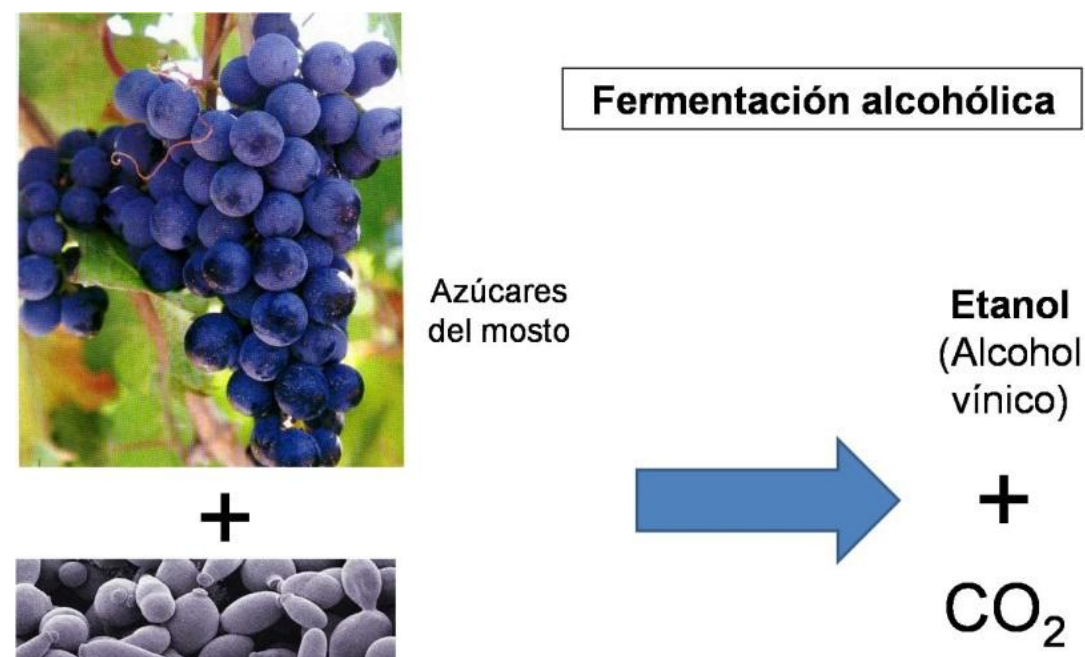

Levaduras

Esta operación, la corrección química de la vendimia, consiste en aumentar la riqueza en azúcares del mosto. Este aumento, denominado a veces enriquecimiento, puede efectuarse básicamente de tres formas ${ }^{18:} 1$ ) por azucaramiento (o chaptalización), 2) por deshidratación parcial del mosto de toda la vendimia o 3) por adición al total de la vendimia de una parte del mosto previamente deshidratado. En definitiva, estas correcciones están básicamente encaminadas a obtener buenos vinos a partir de vendimias en malas condiciones de maduración. Al respecto, en 1905, Gayon decía:

16 Por sobremaduración se entienden todos los procesos tendentes a aumentar la concentración de azúcar en la propia uva. Tradicionalmente estos procesos han sido dos: Dejar pasificar los racimos en la misma cepa o asolear los racimos, ya cortados, extendiéndolos durante cierto tiempo al sol o a la sombra, sobre espartos o colgados de hilos.

17 A veces, en cambio, cuando la cantidad de azúcares en el mosto es demasiado alta para confeccionar el vino que se pretende, es necesario eliminar parte del grado glucométrico, es decir, aguar el mosto. Además de la corrección del azúcar existen otras correcciones importantes que a veces deben hacerse, especialmente la que tiene que ver con el grado de acidez del mosto, acidificándose o desacidificándose artificialmente, según sea el caso o la necesidad.

18 E. Ribéreau-Gayon, E. Penaud, P. Ribéreau-Gayon, P. Sudraud (1992), Sciences et techniques du vin. Traité d'oenologie. T. III: Vinifications, transformations du vin, Paris 1976 (= Tratado de enología. Ciencias y técnicas del vino. Tomo III: Vinificación. Transformación del vino, Buenos Aires 1992) 1992, 12-13. 
El azucaramiento, practicado en dosis moderadas, con mosto de primera calidad, es una operación legítima y recomendable, pues la misma es susceptible de mejorar muy sensiblemente el vino, de facilitar su conservación y de acrecentar su valor comercial"19.

Un sentido similar tenía el mensaje de Columela más de dieciocho siglos antes, aunque el romano lo dijera con otras palabras:

Cualquier clase de vino que pueda durar mucho tiempo sin aderezos pensamos que es el mejor, y que no se debe mezclar absolutamente nada con lo que pueda alterarse su sabor natural, pues lo más excelente es lo que puede agradar por su propia naturaleza. Pero cuando por un defecto propio de la región o de las viñas nuevas el mosto es de mala calidad (...) llevaremos el mosto desde la poza a los calderos del arrope...20.

De los tres procesos mencionados el primero consiste en la adición al mosto de azúcar común o sacarosa ${ }^{21}$ y tiene su origen en el médico y químico francés Jean Antoine Claude Chaptal (1756-1832), ministro del Interior con el Directorio de Napoleón, consejero de Estado y miembro del Instituto Nacional de Francia y de numerosas academias y sociedades francesas $^{22}$. La práctica de la chaptalización es utilizada actualmente

19 U. Gayon, Préparation et conservation du vin, Bordeaux 1905, citado por E. RIBÉREAUE. Ribéreau-Gayon, E. Penaud, P. Ribéreau-Gayon, P. Sudraud (1992), Sciences et techniques du vin. Traité d'oenologie. T. III: Vinifications, transformations du vin, Paris 1976 (= Tratado de enología. Ciencias y técnicas del vino. Tomo III: Vinificación. Transformación del vino, Buenos Aires 1992) 1992, 11.

${ }^{20}$ Columela, Re Rustica, 12.19.2-3. Traducción de M. Villarejo y M. García-Denche para la edición del Ministerio de Agricultura (A. Holgado Redondo (ed.), Lucio Junio Moderato Columela, De los trabajos del Campo, Ministerio de Agricultura Pesca y Alimentación, Madrid 1988, 274).

${ }^{21}$ La sacarosa no fermenta por sí misma y debe ser transformada previamente en fructosa y glucosa (los dos azúcares principales que contiene la uva), transformación denominada inversión. En la práctica está demostrado el potencial invertásico de los catalizadores de las levaduras presentes en la uva, que pueden hidrolizar rápidamente la sacarosa (un disacárido) y convertirla en los dos monosacáridos ya citados: glucosa y fructosa (E. Ribéreau-Gayon, E. Penaud, P. Ribéreau-Gayon, P. Sudraud (1992), Sciences et techniques du vin. Traité d'oenologie. T. III: Vinifications, transformations du vin, Paris 1976 (= Tratado de enología. Ciencias y técnicas del vino. Tomo III: Vinificación. Transformación del vino, Buenos Aires 1992) 1992, pp. 12-13; L. Ibar (2002), Cómo se hace un buen vino, Barcelona, p. 65 .

${ }^{22}$ Expuso su descubrimiento en un libro con el título Traité théorique et pratique sur la culture de la vigne, avec l'art de faire le vin, les eaux-de-vie, esprit-de-vin, vinaigres simples et composés. Ouvrage dans lequel se trouvent les meilleures méthodes pour faire, gouverner et perfectioner les vins et eaux-de-vie; avec xxi planches représentant les diverses espèces de vignes; les machines et instrumens servant à la fabrication des vins et eaux-de-vie. Publicado en Delalain hijos, Paris 1801. Probablemente se trate del primer escritor sobre viticultura y vinificación que trabajó basándose más en la evidencia científica de sus días que partiendo de las enseñanzas de los clásicos. 
sobre todo en Francia y Alemania, donde no todos los años las uvas reciben el sol que necesitan.

El segundo proceso consiste en la adición al total de la vendimia de un parte del mosto previamente deshidratado. Actualmente este procedimiento se realiza por cualquier método autorizado diferente al fuego directo, de forma que su densidad a $20^{\circ} \mathrm{C}$ no sea inferior a 1240 , lo cual corresponde a alrededor de $575 \mathrm{~g} / 1$ de azúcar (según la antigua expresión, alrededor de $28^{\circ}$ Baumé) ${ }^{23}$. Por la misma razón que el agregado de azúcar, la adición de mosto concentrado debe efectuarse antes o al principio de la fermentación ${ }^{24}$.

El tercer proceso posible es la deshidratación parcial del mosto de toda la vendimia. Según los enólogos y el gusto modernos, esta operación no debe conducir a reducir en más de un $20 \%$ el volumen inicial del mosto 25 , ni a aumentar en ningún caso en más de $2^{\circ}$ el título alcoholimétrico natural del mosto de partida; ello tiene por objeto la obtención de productos que puedan fermentar normalmente sin disolución.

El descubrimiento realizado por Chaptal era ignorado por los romanos. Sin embargo, las fuentes literarias sí nos permiten comprobar que los romanos conocían los otros dos procedimientos citados para la corrección de la vendimia, aunque lo normal fue que utilizasen el segundo, es decir, la deshidratación del mosto hasta conseguir arrope. En efecto, varios autores antiguos nos aportan datos suficientes como para conocer la forma en la que se realizaban estos procedimientos, con la variante de que la única forma conocida en época romana de deshidratar el mosto era cociéndolo a fuego directo, puesto que no existían los modernos procesos

\footnotetext{
${ }^{23}$ Es decir, los manuales de enología moderna recomiendan que un mosto, por ejemplo con una cantidad de azúcar de 191,6 gr/l (que teóricamente daría un vino de aproximadamente $11^{\circ}$ ), se puede reducir hasta $1 / 3$ de su volumen inicial hasta alcanzar los 575 gramos de azúcares por litro. Así, los tratadistas modernos recomiendan reducir el mosto en la misma cantidad que los enólogos romanos reducían el suyo (por ejemplo, E. Ribéreau-Gayon, E. Penaud, P. Ribéreau-Gayon, P. Sudraud (1992), Sciences et techniques du vin. Traité d'oenologie. T. III: Vinifications, transformations du vin, Paris 1976 (= Tratado de enología. Ciencias y técnicas del vino. Tomo III: Vinificación. Transformación del vino, Buenos Aires 1992) 1992, 14-15).

${ }^{24}$ E. Ribéreau-Gayon, E. Penaud, P. Ribéreau-Gayon, P. Sudraud (1992), Sciences et techniques du vin. Traité d'oenologie. T. III: Vinifications, transformations du vin, Paris 1976 (= Tratado de enología. Ciencias y técnicas del vino. Tomo III: Vinificación. Transformación del vino, Buenos Aires 1992) 1992, 14-15.

${ }_{25}$ Por su parte, entre los antiguos, Columela aconsejaba la reducción del 10\% del mosto de toda la vendimia (Columela, Re Rustica, 12.20.8), mientras que Demócrito aconsejaba reducirlo hasta un 20\% (Geopónicas 7.4).
} 
de deshidratación al vacío (que impide el proceso de caramelización del mosto).

Las fuentes latinas llaman a estos mostos cocidos o arropes básicamente con tres nombres diversos, que también cambian con el tiempo: defrutum, sapa y caroenum ${ }^{26}$. La única diferencia existente entre ellos está en el grado de concentración de azúcares de cada compuesto, es decir, en la cantidad de agua que se conserva en cada uno (véase un resumen en la tabla 1). En realidad, tanto el defrutum como la sapa o el caroenum son exactamente lo mismo: se trata de un concentrado de zumo de uva que los especialistas romanos recomiendan se realize cociendo zumo de uva en grandes calderas de plomo ${ }^{27}$.

\begin{tabular}{|l|l|l|l|}
\hline & Defrutum & Sapa & Caroenum \\
\hline Catón & Sin precisar. & Sin precisar. & --- \\
\hline Varrón & Reduce del $100 \%$ al $33 \%$ & Reduce del $100 \%$ al $50 \%$ & --- \\
\hline Columela & Reduce del $100 \%$ al $33 \%$ & Reduce del $100 \%$ al $50 \%$ & --- \\
\hline Plinio & Reduce del $100 \%$ al $50 \%$ & Reduce del $100 \%$ al 33\% & --- \\
\hline Paladio & En cuanto se espesa & Reduce del 100\% al 33\% & Reduce del 100\% al $66 \%$ \\
\hline Isidoro & Reduce del 100\% al 50\% & Reduce del 100\% al 33\% & Reduce del 100\% al $66 \%$ \\
\hline
\end{tabular}

Tabla 1.- Porcentaje de reducción del mosto según los diferentes autores latinos

El arrope o mosto cocido en sus diferentes variantes (defrutum, sapa y caroenum) tenía numerosas utilidades, pero las principales eran dos: En primer lugar, su utilización en la enología para añadirlo a las cosechas de uva que, al no haber tenido suficiente luz solar eran deficientes en glucosa y por tanto estaban en peligro de producir vinos deficientes. En segundo lugar, como edulcorante 28 . De hecho, desde época romana y hasta la aparición del azúcar de remolacha, el arrope fue siempre el azúcar de los pobres en la Europa meridional, pues era mucho más barato que la miel o el azúcar de caña.

Por tanto, volviendo a la posibilidad de que los emperadores y aristócratas romanos se hubiesen envenenado por el consumo de vino contaminado con plomo, nada más lejos de la realidad. Como hemos visto, la teoría de la vinificación romana exigía que los vinos fuesen lo más puros posibles y como muestra tenemos la cita de Columela que ya

26 A. Aguilera Martín (2004), "Defrutum, sapa y caroenum. Tres nombres y un producto: arrope", en C. Carreras, A. Aguilera et alii, Culip VIII i les àmfores Haltern 70, Barcelona 2004, 120-132.

27 A. Aguilera Martín (2004), "Defrutum, sapa y caroenum. Tres nombres y un producto: arrope", en C. Carreras, A. Aguilera et alii, Culip VIII $i$ les àmfores Haltern 70, Barcelona 2004, 120-132.

28 A. Aguilera Martín (2004), "Defrutum, sapa y caroenum. Tres nombres y un producto: arrope", en C. Carreras, A. Aguilera et alii, Culip VIII i les àmfores Haltern 70, Barcelona 2004, 120-132. 
he mencionado antes, aunque no es la única. El arrope, según esa misma teoría enológica, sólo debía añadirse a los mostos que necesitasen un enriquecimiento en azúcares. Por ello, el arrope era el producto que más se utilizaba en la falsificación y adulteración de los vinos romanos. Y precisamente esos no eran los que normalmente consumían los más ricos. En definitiva, como decía Plinio el Viejo (14.130):

Catón manda que el vino se "prepare" (así dice él) con una cuadragésima parte de lejía de ceniza cocida con défruto por cada 20 ánforas, o con una libra y media de sal y a veces con mármol triturado. Hace también mención del azufre, pero de la resina sólo en último lugar. Manda sobre todo añadir al vino que está comenzando a madurar el mosto que él llama tortivo y que nosotros conocemos como el de último prensado. Sabemos que se añaden también colorantes para teñirlo, a modo de pigmentos del vino, y así gana cuerpo. ¡Con tantos brebajes forzamos al vino para que agrade, y nos admiramos de que resulte dañino! Y la prueba de que se va a echar a perder reside en que cambia el color de una lámina de plomo puesta en su interior ${ }^{29}$.

Lo mismo, aunque utilizando un lenguaje algo más novelesco, decía Henderson 18 siglos después, refiriéndose al mismo problema ${ }^{30}$ :

There is (...) a certain fraternity of chemical operators, who work underground in holes, caverns, and dark retirements, to conceal their mysteries from the eyes and observations of mankind. These subterraneous philosophers are daily employed in the transmutation of liquors, and, by the power of magical drugs and incantations, raising, under the streets of London, the choicest products of the hills and valleys of France. They can squeeze Bourdeaux out of the sloe, and draw Champagne from an apple (...) the reduction of duty on Cape wines enables the adepts of the present day to employ, as occasion may require, a more substantial and convenient menstruum for their preparations, than that formerly used. By mixing these wines with the lees of other kinds, and tinting and compounding them with various drugs, they endeavour to counterfeit the more costly vintages of Spain and Portugal, and even of France. (...) The high impost on the choicer wines, however, holds forth so strong a temptation to embark in this disreputable trade, that we must lay our account with its continuance, until the return to more moderate and equal rates shall remove the causes from which it has chiefly sprung".

Unos vinos, claro está, que no iban a beber ni los sires ni los lores del imperio británico. Of course!

${ }^{29}$ Un compendio bizantino del siglo IX, las Geopónicas, describe así el proceso (7.15.1718): "se fabrica una laminilla de plomo y se pega en el tapón de la tinaja con cera, antes de cerrarla. A los cuarenta días se abre el recipiente: si la laminilla no se ha alterado, el vino está sano, pero si aparece de un color blanquecino, es que el vino va a estropearse".

${ }^{30}$ A. Henderson, History of Ancient and Modern Wines, London 1824, p. 338-339. 